\title{
CONFOCAL MICROSCOPY STUDIES OF LIVING FUNGAL HYPHAE AND CONIDIA USING RHENIUM (I) TRICARBONYL COMPLEXES AS FLUORESCENT DYES.
}

\author{
ALEXANDER CARREÑO,${ }^{A^{*}}$ KAMILA FERNÁNDEZ, ${ }^{B}$ FELIPE SÁEZ-CORTEZ, ${ }^{B}$ CAROLINA OTERO,${ }^{C}$ RAMIRO \\ ARRATIA-PÉREZ, ${ }^{A} J U A N A$. FUENTES, ${ }^{D}$ AND RUBÉN POLANCO ${ }^{B^{*}}$ \\ ${ }^{a}$ Center for Applied Nanosciences (CANS), Universidad Andres Bello, República 275, Santiago, Chile, Zip Code: 8370146. \\ www.cans.cl \\ ${ }^{b}$ Centro de Biotecnología Vegetal (CBV), Facultad de Ciencias de la Vida, Universidad Andres Bello, República 330, Santiago, \\ Chile. \\ ${ }^{c}$ Escuela de Química y Farmacia. Facultad de Medicina. Universidad Andres Bello, República 252, Santiago, Chile. \\ ${ }^{d}$ Laboratorio de Genética y Patogénesis Bacteriana, Facultad de Ciencias de la Vida, Universidad Andres Bello, República 330, \\ Santiago, Chile.
}

\section{ABSTRACT}

Botrytis cinerea is a ubiquitous necrotrophic filamentous fungal pathogen, causing the "grey mold" disease in a wide range of plants, including species of importance in the food industry. Recently, we reported the use of $f a c-\left[\operatorname{Re}(\mathrm{I})(\mathrm{CO})_{3}\left(2,2^{\prime}\right.\right.$ '-bpy $\left.) \mathbf{L}\right] \mathrm{PF}{ }_{6}(\mathbf{C} 3)$ and $f a c$ - $\left[\operatorname{Re}(\mathrm{I})(\mathrm{CO})_{3}\left(4,4^{\prime}\right.\right.$-dimethyl-2,2'-bpy) $\left.\mathbf{L}\right] \mathrm{PF}{ }_{6}(\mathbf{C} 4)$ complexes as biomarkers for yeasts and bacteria. Nevertheless, the use of these complexes to stain filamentous fungi, such as Botrytis cinerea, has not been explored so far. Since Botrytis cinerea exhibits a dynamic multilayer cell wall that changes the composition during normal growth, in both their hyphae and conidia, is not possible to directly extrapolate the use of both $\mathbf{C 3}$ and $\mathbf{C 4}$ as biomarkers for Botrytis cinerea without an experimental approach. In this work, we explored new features of the luminescent compounds $\mathbf{C 3}$ and $\mathbf{C 4}$ as biomarkers for the higher filamentous fungi Botrytis cinerea, including conidia and juvenile hyphae. We found that, with the new protocol proposed, both $\mathbf{C 3}$ and $\mathbf{C 4}$ were suitable to stain conidia with a simple procedure since no cell permeabilization is required. Additionally, these results suggest that $\mathbf{C 3}$ and $\mathbf{C 4}$ can selectively stain living conidia, allowing the differentiation from non-germinating conidia. This point opens a new focus of development for rhenium (I) tricarbonyl complexes as new fluorescent biomarkers for Botrytis cinerea with potential properties as vital staining.

\section{INTRODUCTION}

Botrytis cinerea is a ubiquitous necrotrophic filamentous fungal pathogen, causing the "grey mold" disease in a wide range of hosts, infecting over 200 different plant species. This fungal pathogen generates enormous damage during plant growth (affecting the general plant well-being, diminishing the yield and fruit quality), but also in the post-harvest stage of the final products (rotting away the infected fruit) [1]. The table grape industry in Chile is highly important, being the third most important market in terms of economic impact (1400 million USD per year). This industry is highly affected by Botrytis cinerea, producing losses that can reach up to $50 \%$ of the production, only if considered the post-harvest condition [2]. In this sense, the development of new tools to study Botrytis cinerea will be very useful de develop improved strategies to attack this fungal pathogen.

The photophysical attributes of rhenium (I) tricarbonyl complexes [ $\mathrm{fac}$ $\operatorname{Re}(\mathrm{I})(\mathrm{CO})_{3}(\mathrm{~N}, \mathrm{~N})(\mathrm{L})^{\mathrm{n}}$, where $\mathrm{N}, \mathrm{N}$ is a bidentate ligand, $\mathrm{L}$ is a monodentated ancillary ligands, and $\mathrm{n}$ is 0 or $1+]$, has attracted considerable attention due to some of their properties. Interestingly, photophysical properties can be modulated depending on the ligand nature, whose substitution directly affect the emission pattern, optical and electronic properties, Stokes shifts, emission lifetimes and enhanced photostability [3-7]. More recently, other works reported that changes the ancillary ligand can also modulate other properties such as solubility, lipophilicity, as well as cytotoxicity, properties that must be considered potential applications related to biological systems [8-11].

The $f a c-\left[\operatorname{Re}(\mathrm{I})(\mathrm{CO})_{3}\left(2,2^{\prime}-\mathrm{bpy}\right) \mathrm{L}\right] \mathrm{PF}_{6} \quad(\mathrm{C} 3)$ and $f a c$ - $\left[\mathrm{Re}(\mathrm{I})(\mathrm{CO})_{3}\left(4,4^{\prime}-\right.\right.$ dimethyl-2,2'-bpy)L]PF 6 (C4) complexes (See Scheme 1) have been recently reported $[12,13]$. The luminescent properties of these complexes were tuned by the withdrawing electronic nature of the ancillary ligand L (E-2-((3-aminopyridin-4-ylimino)-methyl)-4,6-di-tert-butylphenol), a pyridine Schiff base presenting an intramolecular hydrogen bond (IHB) [14]. More importantly, C3 and $\mathrm{C} 4$ complexes demonstrated to be suitable fluorophores for prokaryotic (Salmonella enterica, a Gram-negative bacterium) and eukaryotic (Candida albicans and Cryptococcus spp., yeasts) microorganisms, both walled cells, without the need of complementary antibodies [12]. Nevertheless, the use of these complexes to stain filamentous fungi, such as Botrytis cinerea, has not been explored so far. Although $\mathrm{C} 3$ and $\mathrm{C} 4$ can be considered as suitable biomarkers for yeasts (unicellular fungi), the extrapolation of their use in Botrytis cinerea (filamentous multicellular fungi) is not obvious. It has been reported that higher fungi, such as Botrytis cinerea, exhibit a dynamic multilayer cell wall that changes the composition during normal growth [15]. The Botrytis cinerea cell wall is mainly constituted by proteins and neutral sugars (including glucose, arabinose, galactose, xylose and mannose), along with chitin and uronic acids [15]. Interestingly, the cell wall composition changes through the normal growth, where levels of chitin and neutral sugars increase and protein level decreases. In this sense, it has been proposed that the Botrytis cinerea cell wall becomes extensively covalently cross-linked due to aging mycelia [15]. On the other hand, it has been reported that the Botrytis cinerea spore (conidium) also present changes in its envelope, depending on the stage of maturation (germinating and nongerminating spores) $[16,17]$. For that reason, the focus of this work is not the synthesis and characterizations of $\mathrm{C} 3$ and $\mathrm{C} 4$ per se, but exploring the live-cell fluorescence microscopy techniques in Botrytis cinerea, to open new frontiers in the rhenium chemistry applications in our country, since Chile is the most important producer of rhenium in the world. Thus, this work could contribute to the study of the Botrytis cinerea life-cycle using fluorescent staining, and/or to develop a rational design strategy for new fluorescent rhenium (I) tricarbonyl compounds for selective staining of organelles in eukaryotic cells having cell wall.
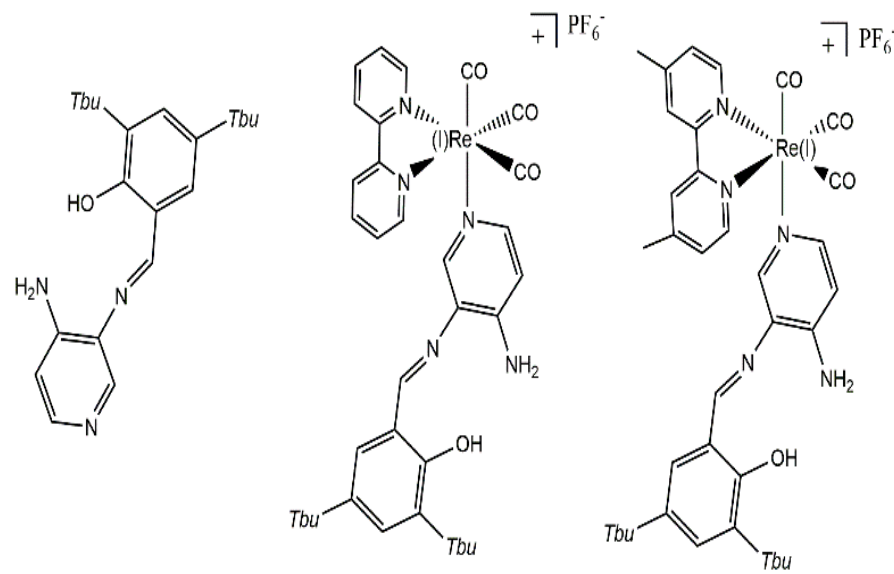

L

C3

C4

Scheme 1. Chemical structure of $E$-2-((3-amino-pyridin-4-ylimino)methyl)-4,6-di-tert-butylphenol (L), fac-[Re(CO) $)_{3}\left(2,2^{\prime}\right.$-bpy)L $] \mathrm{PF}_{6}(\mathrm{C} 3)$ and $f a c$ $\left[\operatorname{Re}(\mathrm{CO})_{3}(4,4\right.$ '-dimethyl-2,2'-bpy)L]PF 6 (C4). 


\section{EXPERIMENTAL SECTION}

All the starting reagents and solvents were purchased from Merck, Aldrich or Winkler and used without further purification.

\subsection{Rhenium (I) tricarbonyl complexes $\mathrm{C} 3$ and $\mathrm{C} 4$ as dyes}

The $\mathrm{C} 3$ and $\mathrm{C} 4$ complexes were synthesized from $\mathrm{C} 1$ ( fac $-\left[\mathrm{Re}(\mathrm{I})(\mathrm{CO})_{3}\left(2,2^{\prime}\right.\right.$ bpy)Br] $)$ and $\mathrm{C} 2(\mathrm{fac}$-[Re( $\mathrm{I})(\mathrm{CO})_{3}(4,4$ '-dimethyl-2,2'-bpy)Br]), respectively [12, $18]$. This method aimed to replace the bromide ancillary ligand by L ((E-2-((3amino-pyridin-4-ylimino)-methyl)-4,6-di-tert-butylphenol)) [12, 13] in both precursors. For more details about the synthesis and characterization, please see the $\mathrm{ESI}^{\dagger}$.

\subsection{Growth condition and staining assays}

2.2.1 Microorganisms and culture conditions: Botrytis cinerea strain B05.10 was obtained from the Phytopathogenic Fungi Laboratory at Andres Bello University (Santiago, Chile). The stock cultures of Botrytis cinerea were first inoculated in a Petri dish containing Potato Dextrose Agar (PDA, Difco) and incubated at $25^{\circ} \mathrm{C}$ in darkness for 5 days. After incubation, Petri dishes were stored at $4{ }^{\circ} \mathrm{C}$ to be used as inoculum for every experiment.

2.2.2 Conidial collection: Botrytis cinerea strain B05.10 was grown on 20 $\mathrm{ml}$ of PDA (Difco) in a Petri dish $(90 \mathrm{~mm} \times 15 \mathrm{~mm})$ for 8 days at $25{ }^{\circ} \mathrm{C}$ in darkness. The mycelium with conidia was collected and mixed with $30 \mathrm{~mL}$ of $\mathrm{NaCl} 0.9 \%$ (Winkler) and $500 \mu \mathrm{L}$ of glass beads in a $50 \mathrm{~mL}$ tube, followed by vigorous shaking to separate the vegetative mycelium from conidia. The mixture was filtered in a funnel with hydrophobic cotton and gauze. Finally, conidial suspension was counted and adjusted to a final concentration of $10^{7}$ conidia per $\mathrm{mL}$.

2.2.3 Conidia staining: One $\mathrm{mL}\left(10^{7}\right.$ conidia/mL $)$ was centrifuged at $10.000 \times g$ for $10 \mathrm{~min}$. The supernatant was discarded to obtain conidia (pellet). Conidia were resuspended in $200 \mu \mathrm{L}$ of a solution of $\mathrm{C} 3$ or $\mathrm{C} 4$ (final concentration $200 \mu \mathrm{g} / \mathrm{mL}$ ) and incubated for $24 \mathrm{~h}$ at $37{ }^{\circ} \mathrm{C}$ or $65{ }^{\circ} \mathrm{C}$ on a thermoregulated bath. Conidia were washed twice with distilled water to remove the unbound fluorescent staining. Conidia were then transferred to a new centrifuge tube and washed again twice with distilled water. Finally, conidia were resuspended in $200 \mu \mathrm{L}$ of distilled water. To visualize the results, $1 \mu \mathrm{L}$ of the stained conidia suspension was placed in a microscope slide and observed with a confocal microscope. As controls, we used water or DMSO alone instead of $\mathrm{C} 3$ or $\mathrm{C} 4$ solutions.

2.2.4 Conidial germination assay: The experiment was performed over a thin layer of PDA agar in a Petri dish. A circular sheet of cellophane paper (90 $\mathrm{mm}$ diameter, approximately) was placed over the PDA agar prior inoculating $100 \mu \mathrm{L}\left(2 \times 10^{5}\right.$ conidia $\left./ \mathrm{mL}\right)$ of Botrytis cinerea strain B05.10. The inoculated dish was incubated at $25^{\circ} \mathrm{C}$ for $24 \mathrm{~h}$.

2.2.5 Germinated conidia staining: A piece of cellophane paper $(0.5 \times 0.1$ $\mathrm{cm}$, approximately) was cut with a sterile scalpel from an overnight conidia culture grown on a Petri dish with PDA covered with cellophane. This piece of cellophane with germinated conidia was deposited inside a microcentrifuge tube. Conidia were mixed with either C3 or C4 (final concentration $200 \mu \mathrm{g} / \mathrm{mL}$ ) and incubated at $65^{\circ} \mathrm{C}$ for $24 \mathrm{~h}$. Conidia were observed with confocal microscopy. As controls, we used water or DMSO alone instead of $\mathrm{C} 3$ or $\mathrm{C} 4$ solutions.

\subsection{Fluorescence microscopy studies}

Conidia (or germinated conidia), were mixed with $\mathrm{C} 3$ or $\mathrm{C} 4$ (final concentration $200 \mu \mathrm{g} / \mathrm{mL}$ ), incubated for 24 hours at $37{ }^{\circ} \mathrm{C}$ or $65{ }^{\circ} \mathrm{C}$ as described above. Fluorescence emission was obtained by laser excitation at $405 \mathrm{~nm}$ for both $\mathrm{C} 3$ and $\mathrm{C} 4$. Emission was collected with a long-pass emission filter in the range of 535 to 655 for the two rhenium (I) complexes. Fluorescence was analyzed using an Olympus BX63 fluorescent microscope (Shinjuku, Tokyo, Japan) using a filter system consisting of an excitation between 330 and $385 \mathrm{~nm}$ and a long-pass emission filter for wavelengths higher than $420 \mathrm{~nm}$ for detection.

\section{RESULTS AND DISCUSSION}

(E-2-((3-amino-pyridin-4-ylimino)-methyl)-4,6-di-tert-butylphenol) ancillary ligand (L), C3 and C4 complexes were synthesized and characterized by FTIR and ${ }^{1} \mathrm{H}$ NMR to confirm its purity. We obtained similar results to those previously reported $[12,13]$. $\mathrm{L}$, as a ligand, is not luminescence itself $[12,19]$.

Regarding photophysical characterization of $\operatorname{Re}(\mathrm{I})$ complexes, we already disclosed a comprehensive characterization of both $\mathrm{C} 3$ and $\mathrm{C} 4$ [12, 13]. Both complexes present different emission spectra (C3: broad emission with $610 \mathrm{~nm}$ maximum; C4: less broad emission with $560 \mathrm{~nm}$ maximum) under the same excitation conditions (445 nm). In addition, both C3 and C4 exhibit large Stokes shifts (244 and $199 \mathrm{~nm}$ ), respectively, evidencing a wide change in the dipole moment between the ground and excited states. On the other hand, both $\mathrm{C} 3$ and C4 complexes present a weak emission, accompanied with short lifetime of less than $10 \mathrm{~ns}$. This phenomenon was attributed to intramolecular electron transfer quenching of the ${ }^{3}$ MLCT excited state by the phenolic substituent on the ancillary ligand, couple to proton transfer from the phenolic ring to the ancillary ligand (intramolecular quenching) $[12,13,20,21]$.

In order to study the suitability of $\mathrm{C} 3$ and $\mathrm{C} 4$ as biomarkers for Botrytis cinerea, we performed confocal microscopy with conidia (spores) and hyphae. The low cytotoxicity of these complexes was already shown for several biological models, including walled-cells such as fungi and bacteria, as well as with non-walled cells, such as mammalian epithelial cell lines [12]. To assess the suitability of $\mathrm{C} 3$ and $\mathrm{C} 4$ as biomarkers for Botrytis cinerea, we tested both conidia (asexual fungal spores) and hyphae. For conidia, Botrytis cinerea was incubated in PDA for 8 days prior collecting spores. For staining, we first used a similar protocol already reported to stain yeasts (unicellular fungi) with related rhenium complexes $[12,22]$. Previously, it has been reported that an incubation at $37{ }^{\circ} \mathrm{C}$ during 5 to 15 minutes is enough to stain fungal cells. [12, 22]. Nevertheless, we were unable to fluorescently stain Botrytis cinerea conidia with this protocol (data not shown). Botrytis cinerea conidia show a 2-layered cell wall, a thin electron-dense outer layer and a thicker electron-transparent inner layer $[16,17]$. We speculate that the presence of these structures could explain these discrepancies between yeasts and Botrytis cinerea conidia regarding the staining with these compounds. For that reason, we performed some modifications. First, we extended the incubation time of the mix conidia/rhenium complexes from $15 \mathrm{~min}$ to $24 \mathrm{~h}$ at $37^{\circ} \mathrm{C}$. As shown in Supplementary Figure S1 in the ESI, we obtained better results, especially with $\mathrm{C} 4$, showing that these complexes have some potential as biomarkers for fungal spores of higher fungi. Other biological structures presenting multilayered coats are also hard to stain due to a relative impermeability, such as bacterial spores [23], where the incubation at higher temperatures highly contributes to increase permeability and favor the dye uptake, as in the classical Schaeffer-Fulton stain [24]. In this context, we incubated Botrytis cinerea conidia with either $\mathrm{C} 3$ or $\mathrm{C} 4$ at $65{ }^{\circ} \mathrm{C}$ for $24 \mathrm{~h}$. As shown in Figure 1, both $\mathrm{C} 3$ and $\mathrm{C} 4$ revealed the presence of fluorescent conidia with confocal microscopy, demonstrating that, with a suitable protocol, these compounds are also useful for this cell type. Furthermore, our results suggest that both $\mathrm{C} 3$ and $\mathrm{C} 4$ remain retained by the inner layer $[16,17]$, since it is possible to observe that an unstained area between the outer layer and a central structure (Figure 1).

As a next step, we tested both $\mathrm{C} 3$ and $\mathrm{C} 4$ as biomarkers to stain juvenile hyphae. As previously described, Botrytis cinerea shows a dynamic and complex multilayer cell wall, which changes its composition, and plausibly its properties, during the cell growth [15]. In addition, as well as for hyphae, the outer layers of conidia change during germination, where the dormant spore present only 2 layers (inner and outer layers) whereas the germinating spore develop three new layers between the original cell wall and the cytoplasm. In addition, the thickness of conidia increases approximately a $30 \%$ during germination [25]. Again, it is not possible to directly extrapolate results obtained with conidia to juvenile hyphae without experimentation due to their continuous structural changes in the cell envelope during growth. Thus, to test whether $\mathrm{C} 3$ and $\mathrm{C} 4$ are also useful to stain Botrytis cinerea juvenile hyphae, we performed a similar protocol to that described for the Figure 1. As observed in the Figure 2, both C3 and C4 were able to stain juvenile hyphae. Interestingly, non-germinating conidia, exhibiting a denser structure, seemed to be almost completely excluded from staining. These condensed conidia (revealed by a darker coloration) resemble typical dormant conidia but, judging by the rest of the conidia already germinated (and forming a juvenile hyphae), it is possible that those conidia are dead or unable to complete germination. Considering that most conidia are easily stained by this same protocol (Figure 1), both $\mathrm{C} 3$ and $\mathrm{C} 4$ might be considered in the development of a new vital staining that potentially discriminates viable conidia from non-viable ones. 


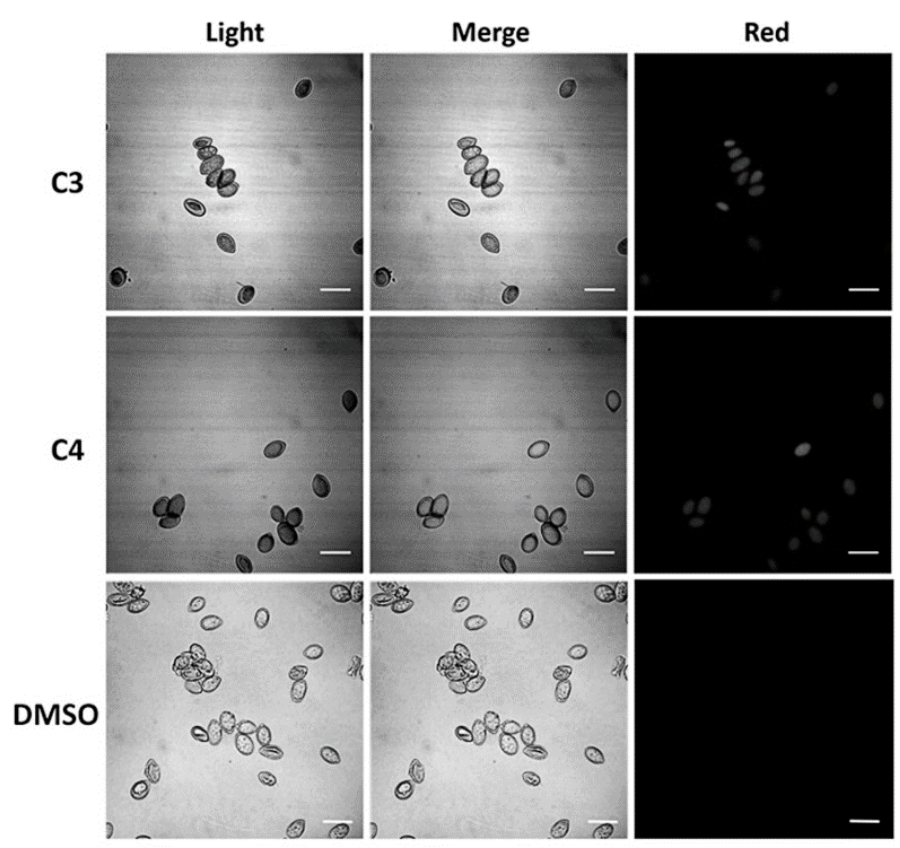

Figure 1. Conidia stained with $\mathrm{C} 3$ and $\mathrm{C} 4$. Botrytis cinerea conidia were incubated with $200 \mu \mathrm{g} / \mathrm{mL}$ (final concentration) either $\mathrm{C} 3$ or $\mathrm{C} 4$ for $24 \mathrm{~h}$ at $65^{\circ} \mathrm{C}$ and analyzed by fluorescence microscopy. As control, Botrytis cinerea conidia were incubated with DMSO (vehicle) for $24 \mathrm{~h}$ at $65^{\circ} \mathrm{C}$ to set the detection threshold. The "Red channel" (Red), corresponds to the excitation of $405 \mathrm{~nm}$ and emission collected in a range of 555 to $625 \mathrm{~nm}$. In all cases, microorganisms were observed fresh. The white bars represent $10 \mu \mathrm{m}$.
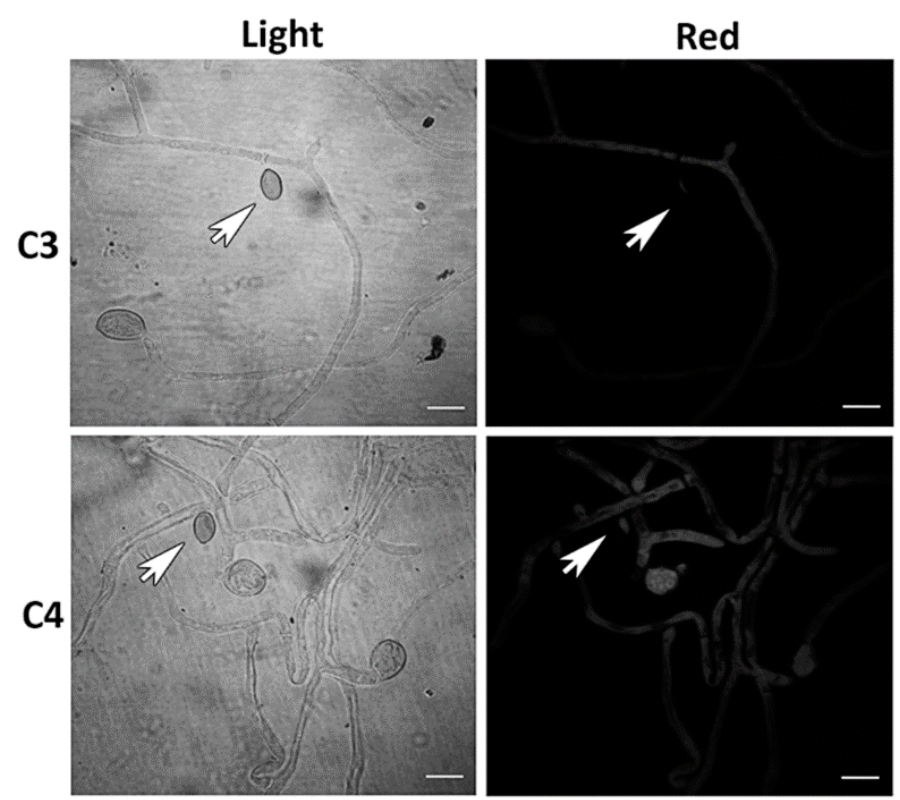

Figure 2. Juvenile hyphae staining. Germinated conidia of Botrytis cinerea were seeded on coverslips and incubated with $200 \mu \mathrm{g} / \mathrm{mL}$ (final concentration) of either $\mathrm{C} 3$ or $\mathrm{C} 4$, for $24 \mathrm{~h}$ at $65{ }^{\circ} \mathrm{C}$ prior being fixed and analyzed by fluorescence microscopy. Arrowheads show non-germinating conidia, which virtually exhibited no staining. Bar size $10 \mu \mathrm{m}$.

Considering that it is impossible to control the exact concentration of fluorophores inside the cells, it is important to remark that there is a possibility of self-quenching inside the biological models. This phenomenon could be affecting the image taken by the microscope. For that reason, it is important to experimentally assess the best protocol to stain cells, including concentration used and time of incubation, in order to improve the technique.

\section{CONCLUSION}

In this work, we explored new features of the luminescent compounds C3 and $\mathrm{C} 4$ as biomarkers for the higher filamentous fungi Botrytis cinerea, including conidia and juvenile hyphae. We found that, with the new protocol proposed, both $\mathrm{C} 3$ and $\mathrm{C} 4$ were suitable to stain conidia with a simple procedure since no cell permeabilization is required. Additionally, these results suggest that $\mathrm{C} 3$ and C4 can selectively stain living conidia, allowing the differentiation from nongerminating conidia. This point opens a new focus of development for rhenium (I) tricarbonyl complexes as new fluorescent biomarkers for Botrytis cinerea with potential properties as vital staining.

\section{ACKNOWLEDGEMENTS}

Funded by FONDECYT 11170637 and Proyecto Núcleo UNAB DI-141916/N; We are grateful to Dr. Ivonne Chávez M. (UC) for instrumental facilities.

\section{REFERENCES}

1. Williamson, B., et al., Botrytis cinerea: the cause of grey mould disease. Mol Plant Pathol, 2007. 8(5): p. 561-80.

2. Tripathi, P., N.K. Dubey, and A.K. Shukla, Use of some essential oils as post-harvest botanical fungicides in the management of grey mould of grapes caused by Botrytis cinerea. World Journal of Microbiology and Biotechnology, 2007. 24(1): p. 39-46.

3. Gonçalves, M.R. and K.P.M. Frin, Synthesis, characterization, photophysical and electrochemical properties of rhenium(I) tricarbonyl diimine complexes with triphenylphosphine ligand. Polyhedron, 2017. 132: p. $20-27$.

4. Mukuta, T., et al., Photochemical Processes in a Rhenium(I) Tricarbonyl NHeterocyclic Carbene Complex Studied by Time-Resolved Measurements. Inorg Chem, 2017. 56(6): p. 3404-3413.

5. Machura, B., et al., Tricarbonyl rhenium(I) complex of benzothiazole Synthesis, spectroscopic characterization, X-ray crystal structure and DFT calculations. Journal of Organometallic Chemistry, 2013. 724: p. 82-87.

6. Sacksteder, L., et al., Luminescence Studies of Pyridine Alpha-Diimine Rhenium(I) Tricarbonyl Complexes. Inorg Chem, 1990. 29(21): p. 43354340 .

7. Kia, R. and F. Safari, Synthesis, spectral and structural characterization and computational studies of rhenium(I)-tricarbonyl nitrito complexes of 2,2'bipyridine and 2,9-dimethylphenanthroline ligands: $\pi$-Accepting character of the diimine ligands. Inorganica Chimica Acta, 2016. 453: p. 357-368

8. Kaplanis, M., et al., Re(I) tricarbonyl complex of 1,10-phenanthroline-5,6dione: DNA binding, cytotoxicity, anti-inflammatory and anti-coagulant effects towards platelet activating factor. J Inorg Biochem, 2014. 135: p. 19.

9. Thorp-Greenwood, F.L., An Introduction to Organometallic Complexes in Fluorescence Cell Imaging: Current Applications and Future Prospects. Organometallics, 2012. 31(16): p. 5686-5692.

10. Raszeja, L.J., et al., Asymmetric rhenium tricarbonyl complexes show superior luminescence properties in live cell imaging. Chem Commun (Camb), 2017. 53(5): p. 905-908

11. Thorp-Greenwood, F.L., et al., Tris(rhenium fac-tricarbonyl) Polypyridine Functionalized Cyclotriguaiacylene Ligands with Rich and Varied Emission. Organometallics, 2016. 35(11): p. 1632-1642.

12. Carreno, A., et al., Fluorescence probes for prokaryotic and eukaryotic cells using $\operatorname{Re}(C O)(3)(+)$ complexes with an electron withdrawing ancillary ligand. New Journal of Chemistry, 2016. 40(9): p. 7687-7700.

13. Carreño, A., et al., X-ray diffraction and relativistic DFT studies on the molecular biomarker fac-Re(CO)3(4,4'-dimethyl-2,2'-bpy)(E-2-((3-aminopyridin-4-ylimino)-methyl)-4,6-di-tert-butylphenol)(PF6). Chemical Papers, 2017. 71(10): p. 2011-2022.

14. Carreño, A., et al., Spectral, theoretical characterization and antifungal properties of two phenol derivative Schiff bases with an intramolecular hydrogen bond. New J. Chem., 2015. 39(10): p. 7822-7831.

15. Cantu, D., et al., Characterization of the cell wall of the ubiquitous plant pathogen Botrytis cinerea. Mycol Res, 2009. 113(Pt 12): p. 1396-403.

16. Buckley, P.M., V.E. Sjaholm, and N.F. Sommer, Electron microscopy of Botrytis cinerea conidia. J Bacteriol, 1966. 91(5): p. 2037-44.

17. Hawker, L.E. and R.J. Hendy, An Electron-Microscope Study of Germination of Conidia of Botrytis cinerea. J Gen Microbiol, 1963. 33: p. 43-6. 
18. Carreno, A., et al., Experimental and theoretical studies of the ancillary ligand (E)-2-((3-amino-pyridin-4-ylimino)-methyl)-4,6-di-tert-butylphenol in the rhenium(I) core. New Journal of Chemistry, 2015. 39(7): p. 57255734.

19. Carreno, A., et al., Spectral, theoretical characterization and antifungal properties of two phenol derivative Schiff bases with an intramolecular hydrogen bond. New Journal of Chemistry, 2015. 39(10): p. 7822-7831.

20. Herzog, W., et al., Electron transfer between hydrogen-bonded pyridylphenols and a photoexcited rhenium(I) complex. Chemphyschem, 2013. 14(6): p. 1168-76.

21. Wenger, O.S., Proton-coupled electron transfer with photoexcited metal complexes. Acc Chem Res, 2013. 46(7): p. 1517-26.
22. Carreño, A., et al., Substituted bidentate and ancillary ligands modulate the bioimaging properties of the classical Re(i) tricarbonyl core with yeasts and bacteria. New J. Chem., 2017. 41(5): p. 2140-2147.

23. Leuschner, R.G. and P.J. Lillford, Investigation of bacterial spore structure by high resolution solid-state nuclear magnetic resonance spectroscopy and transmission electron microscopy. Int J Food Microbiol, 2001. 63(1-2): p. 35-50.

24. Hussey, M.A. and A. Zayaitz, Endospore stain protocol. American Society of Microbiology, 2007.

25. Gull, K. and A.P.J. Trinci, Fine Structure of Spore Germination in Botrytis cinerea. Journal of General Microbiology, 1971. 68(2): p. 207-220. 